\title{
Spontaneous pneumomediastinum following pneumonia in a 23-year-old male patient
}

\author{
Yusuf Kayar1, Nüket Bayram Kayar², Tuncay Şahutoğlu33, Venkatanarayana Gangarapu1 \\ 1 Department of Internal Medicine, Division of Gastroenterology, Bezmialem Vakif University, Istanbul \\ 2 Department of Family Practice, Bağcılar Education and Research Hospital, Istanbul \\ 3 Department of Internal Medicine, Sisli Etfal Education and Research Hospital, Istanbul, Turkey
}

\begin{abstract}
Spontaneous pneumomediastinum (SPM) is defined as the presence of interstitial air in the mediastinum without any apparent precipitating factor. We present a case of a 23 -year-old male patient, who has been referred to our outpatient clinic with the complaints of sudden chest pain, dyspnea followed by pneumonia and was diagnosed as SPM. The patient was treated with ampicillin sulbactam (4 gr/day) and methylprednisolon ( $20 \mathrm{mg} /$ day) for 4 days. and oral intake was stopped during treatment. Post treatment, it was observed that the crepitations were disappeared thoroughly and vesicular sounds were heard by oscultation. The control values of arterial blood gas was as following: $\mathrm{pH}=7.39 \mathrm{pO}_{2}=95 \mathrm{mmHg}, \mathrm{pCO}_{2}=37 \mathrm{mmHg}, \mathrm{SaO}_{2}$ : $97 \%$. In the $5^{\text {th }}$ day his oral intake started and he was discharged.
\end{abstract}

\section{Introduction}

Spontaneous pneumomediastinum (SPM) is defined as the presence of interstitial air in the mediastinum without any apparent precipitating factor. The pathophysiology of this condition is based on the existence of a pressure gradient between the alveoli and the lung interstitium; this pressure difference may lead to alveolar rupture and the consequent escape of air into the interstitium. Once the air is in the lung interstitium, it flows towards the hilum and the mediastinum along a pressure gradient between the lung periphery and the mediastinum [1]. SPM is a clinical state which has been mostly seen in young patients without any

Corresponding author: Dr. Yusuf Kayar, Department of Internal Medicine, Division of Gastroenterology, Bezmialem Vakif University, Vatan Street, Fatih, 34093 Istanbul, Turkey.

Tel. +90.212.4531700 - Fax +090.212.3735000. E-mail: ykayar@yahoo.com

Key words: Spontaneous pneumomediastinum; dyspnea; chest pain.

Received for publication: 20 May 2014

Accepted for publication: 22 August 2016

CCopyright Y. Kayar et al., 2016

Tipografia PI-ME Editrice, Italy

Monaldi Archives for Chest Disease Pulmonary Series 2016; 83:769

doi: 10.4081/monaldi.2016.769

This article is distributed under the terms of the Creative Commons Attribution Noncommercial License (by-nc 4.0) which permits any noncommercial use, distribution, and reproduction in any medium, provided the original author(s) and source are credited. reason and recover by itself $[2,3]$. We report here of a young patient who was diagnosed with spontaneous pneumomediastinum.

\section{Case Report}

A 23-year-old male has referred to our outpatient clinic with cough, dyspnea, chest pain and handling crackle on his skin. He had been referred to an outpatient clinic with cough and sputum five days ago, and was receipt azitromycin because of the diagnosis of pneumonia. However, the patient who had the feeling of air leakage upwards after every cough and sneezing, has been referred to us with severe chest pain and dyspnea. Physical examination of the patient revealed that he was tachipneic, dyspneic; blood pressure was 120/70; heart rate was 106 per min - rhythmic, respiratory rate was 26 per min; rare rales in the basal sides of right lung, subcutaneous crepitations at bilateral mediastinum and neck. Leucocytes count was $11,300 \mathrm{~mm}^{3}$ and CRP was $28 \mathrm{mg} / \mathrm{L}$. Arterial blood gas was as following: $\mathrm{pH}=7.38, \mathrm{pO}_{2}=59.9 \mathrm{mmHg}, \mathrm{pCO}_{2}=39.4 \mathrm{mmHg}, \mathrm{SaO}_{2}=90.9 \%$.

The patient is a non-smoker and had no complaints of nausea and vomiting. Chest $X$ ray of the patient revealed that there was air within mediastinum, subcutaneous emphysema, peribronchial infiltrations in the middle lobe of right lung (Figure 1). Additionally, computer tomography (CT) scan shows that there was air within mediastinum, subcutaneous emphysema, peribronchial infiltrations in the middle lobe of right lung (Figure 2). Because of the fact that there was no pathological sign in his esophageal passage radiography, gastroscopy was not considered necessary.

\section{Treatment}

The patient whose oral intake was stopped and has given ampicillin/sulbactam (4 gr/day) and methylprednisolone ( $20 \mathrm{mg} /$ day) for his dyspnea. The patient has taken follow-up with chest $\mathrm{X}$ rays daily, during treatment. Post the treatment, it was observed that the crepitations were disappeared thoroughly and vesicular sounds were heard by auscultation. The control values of arterial blood gas was as following: $\mathrm{pH}: 7.39 \mathrm{pO}_{2}: 95 \mathrm{mmHg}, \mathrm{pCO}: 37 \mathrm{mmHg}, \mathrm{SaO}_{2}: 97 \%$. In the $5^{\text {th }}$ day his oral intake started and he was discharged.

\section{Discussion}

Spontaneous pneumomediastinum is a rare clinical state which is seen mostly in young males and usually without any symptoms; and in the symptomatic forms, the symptoms often regress spontaneously [4]. In the literature, it is usually seen in the age of 17-25 [5]. The air passes to the mediastinum and subcutaneous tissue from the area which has 


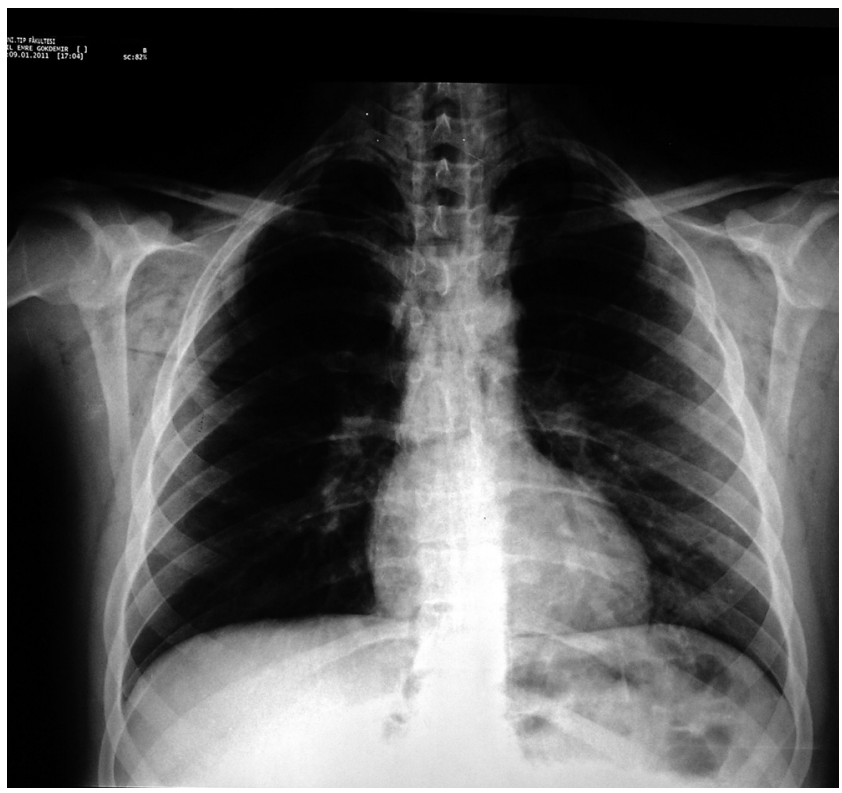

Figure 1. Chest $\mathrm{X}$ ray of the patient revealing air within mediastinum, subcutaneous emphysema, peribronchial infiltrations in the middle lobe of right lung.

been traumatized (terminal alveoli, bronchus, trachea, esophagus) along through the tissues by dissection [6,7]. If the dissection is excessive, the air can spread to neck, face, arms and even to the abdomen. It was reported that the subcutaneous emphysema have spread till the genital area in some cases [6]. If there is a coexisting lung disease, the incidence of SPM increases. Asthma (8-39\%), interstitial lung disease (18\%), pneumonia, bullous lung disease, radiation therapy for the lung cancer are related with SPM [8]. Vomiting (24-36\%), asthma attack (15$24 \%)$, coughing (7-35\%), sneezing (13\%), increased physical activity (30\%), exertion during the birth (4-15\%), shouting, deep breathing, diabetic ketoacidosis, Valsalva maneuver, sarcomas and drugs such as heroin or cocaine usually precipitate SPM. Anorexia nervosa is also a predisposing state for SPM because of the diminished elasticity of the lung tissue. However, in $32-66 \%$ of the SPM cases, there is no precipitating cause [6-9]. Pneumomediastinum can be produced, in general, by three different mechanisms, as follows: i) gas-producing microorganisms present in an infection of the mediastinum or adjacent areas; ii) rupture (both traumatic or not) of the cutaneous or mucosal barriers, especially perforation of the esophagus or tracheobronchial tree, allowing air to enter the mediastinum; and iii) the existence of a decreasing pressure gradient between the alveoli and the lung interstitium that can result in alveolar rupture [10]. The most common symptoms described in the literature are chest pain, dyspnea, and neck pain or discomfort. Chest pain is the most commonly reported symptom in most series and typically presents as an acute, retrosternal, pleuritic pain that may radiate to the neck, back, or shoulders. Other, less common symptoms include odynophagia, cough, dysphonia, back pain, dysphagia, or abdominal pain [11]. In this case the patient also suffered from cough, dyspnea, chest pain and handling crackle on his skin.

Based on the existing literature, SPM has been considered as a benign entity. However, Perna et al. reported that urgent thoracotomy was required for some cases when pre-existing mediastinal shift with moderate tracheal compression and a right minimal pneumothorax were identified by CT. They identified the above mentioned features after 3 $\mathrm{h}$ from admission and performed thoracotomy, and concluded that thoracotomy was a more effective option to avoid a relapse (it allows to
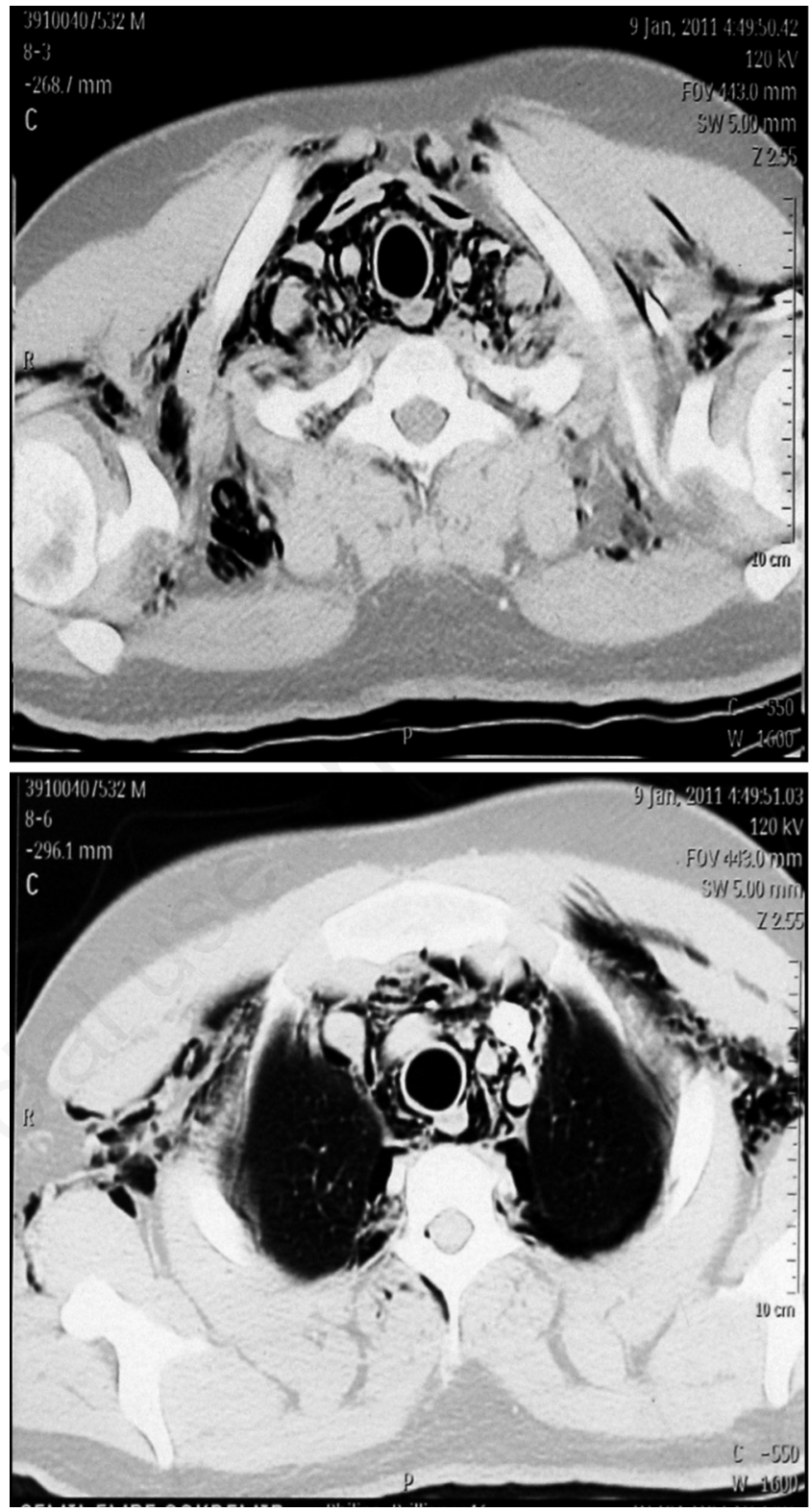

Figure 2. Computer tomography (CT) scans showing air within mediastinum, subcutaneous emphysema, peribronchial infiltrations in the middle lobe of right lung.

open the whole mediastinal pleura) in the presence of a pneumomediastinum associated with a tension pneumothorax [12].

There are three main approaches to the treatment of spontaneous pneumomediastinum: rest, oxygen therapy, and analgesia. Patients respond well to this treatment: clinical manifestations resolve and radiographic signs of the condition diminish [13]. In our case, the patient was treated with ampicillin/sulbactam (4 gr/day) and methylprednisolone ( $20 \mathrm{mg} /$ day) for 4 days, and he recovered after 4 days of treatment. Earlier case reports revealed that there was no significant complications virtually nonexistent and no reported recurrences. However, low incidence of recurrence was noticed in some case reports. Recurrence cases requires outpatient follow-up [14].

In conclusion, this case report enhances knowledge on spontaneous pneumomediastinum management and validity of present treatment procedure. 


\section{References}

1. Macklin MT, Macklin CC. Malignant interstitial emphysema of the lungs and mediastinum as an important occult complication in many respiratory diseases and other conditions: interpretation of the clinical literature in the light of laboratory experiment. Medicine 1944;23:281-358.

2. Jougon JB, Ballester M, Delcambre F, et al. Assessment of spontaneous pneumomediastinum: experience with 12 patients. Ann Thorac Surg 2003;75:1711-1714.

3. Koullias GJ, Korkolis DP, Wang XJ, Hammond GL. Current assessment and management of spontaneous pneumomediastinum: experience in 24 adult patients. Eur J Cardiothorac Surg 2004;25:852-855.

4. Chalumeau M, Le Clainche L, Sayeg N, et al. Spontaneous pneumomediastinum in children. Pediatr Pulmonol 2001;31:67-75.

5. Shen G, Chai Y. Spontaneous pneumomediastinum in adolescents. Chin Med J (Engl) 2007;120:2329-2330.

6. Bilgin M, Kahraman C, Akçalı Y. [Spontan pnömomediastinum].[Article in Turkish]. Toraks Dergisi 2003;4:183-185.

7. Esayag Y, Furer V, Izbicki G. Spontaneous pneumomediastinum: is a chest X-ray enough? A single-center case series. Isr Med Assoc J 2008;10:575-578.

8. Turban JW. Spontaneous pneumomediastinum from running sprints. Case Rep Med 2010;2010:927467.

9. Chu FKC. Spontaneous pneumomediastinum. Hong Kong J Emerg Med 2002;9:168-170.

10. Maunder RJ, Pierson DJ, Hudson LD. Subcutaneous and mediastinal emphysema. Pathophysiology, diagnosis and management. Arch Intern Med 1984;144:1447-1453.

11. Campillo A, Coll A, Soria V, et al. [Neumomediastino espontáneo: estudio descriptivo de nuestra experiencia basada en 36 casos]. [Article in Spanish]. Arch Bronconeumol 2005;41:528-531.

12. Perna V, Vilà E, Guelbenzu JJ, Amat I. Pneumomediastinum: is this really a benign entity? When it can be considered as spontaneous? Our experience in 47 adult patients. Eur J Cardiothorac Surg 2010;37:573-575.

13. Jougon JB, Ballester M, Delcambre F, et al. Assessment of spontaneous pneumomediastinum: experience with 12 patients. Ann Thorac Surg 2003;75:1711-1714.

14. Macia I, Moya J, Ramos R, et al. Spontaneous pneumomediastinum: 41 cases. Eur J Cardiothorac Surg 2007;31:1110-1114. 